\section{Grading of universities}

SIR-While there is much evidence that many university departments were wrongly graded by the University Grants Committee (UGC) earlier this year (see Nature 322, 299; 1986), little attention has been

Percentage distribution of ranks (pooled data).

\begin{tabular}{lcccc} 
& $*$ & A & A & A- \\
Biological science & 8 & 26 & 35 & 31 \\
Physical science & 9 & 28 & 26 & 38 \\
Computing science & 12 & 18 & 24 & 47 \\
Mathematics & 25 & 17 & 34 & 25 \\
Social science & 26 & 11 & 37 & 27 \\
Arts & 20 & 26 & 45 & 8 \\
\hline
\end{tabular}

given to UGC's use of the term "average", the meaning of which appears to have varied from one committee to another.

The table shows the number of different departments placed in the four UGC categories: the starred departments are those whose research was deemed to be of international standard. It will be seen that the distribution of departments among the four categories is odd. For example, in the Arts, the chance of a department being below average was only 1 in 12 , but in computing it was 1 in 2 .

The data show that it is dangerous to use the UGC assessments for a comparison of departments in different fields (or "cost centres"), yet many universities are already doing just this, while UGC is planning to distribute its special equipment grant on the same basis. Earlier criticisms of the assessment procedures have been met with statements to the effect that UGC consulted everybody it could think of, so what else could it have done? In practice, it seems that the information thus gathered may have been less important than the manner in which it was used, with some committees "coming to a conclusion" by hunch. On such a potentially important matter, there should surely have been a formal model for assessment, with the various factors stated explicitly and weighed properly.

I have constructed such a model for physiology departments at British universities. For the assessment of research activity, I used four measures: total research grant income, total grant income from the research councils, total PhD students and the numbers of $\mathrm{PhD}$ students allocated to departments under the research councils' quota system. Departments' scores under the four headings were divided by the numbers of permanent staff and then ranked in numerical order. Departments in the middle third of each distribution, counted as "average", were allocated 2 points and those below and above 1 and 3 points respectively. The sum of the scores under the four headings in principle ranging between 4 and 12 , were again divided into three groups, with that labelled "average" consisting of the

\section{iddle third.}

Statistical analysis shows that, while there is a significant correlation between the two methods of assessment $(p<0.01)$, the measures of research activity I have

used account only for about 40 per cent of the UGC grading, 16 per cent of which appears to have been determined by the size of departments (the larger the size, the higher the grade). It would be interesting if other research areas in British universities could "test the assessors" by means of similar data.

\section{Department of Physiology} and Pharmacology,

St Andrews University,

Fife, Scotland KY16 9TS, UK

\section{Defining darwinism}

SrR-My colleague M. Sinclair, in his letter $^{1}$ on the Imanishi-Halstead issue ${ }^{2}$, correctly insists that without intraspecific competition, any evolutionary theory must be considered to be "non-darwinian"; the baby would be thrown out with the bathwater. I wish to take up another aspect of Halstead's argument, that which maintains that Imanishi's "attack" is "merely a caricature of Darwin".

The categorization of anything that disagrees with "modern darwinism" as a misreading, a misunderstanding, a failure to appreciate the full subleties of the position or, in this case, as bordering on lèse majesté, I find distasteful; I regret to have to say that this is not an isolated example either on Halstead's part ${ }^{3}$ or, more generally, on the part of the average member of the neo-darwinian priesthood ${ }^{4}$.

The very title of Halstead's essay, "Antidarwinian theory in Japan" is provocative, with its implication of a purely negative attitude on the part of Imanishi. This leads me to my suggestion, framed as a question: why should the study of evolution be called "darwinism"? Was Einstein "antinewtonian"? Has the development of modern physics, beyond anything that Newton could possibly have conceived in his day, detracted in the slightest from his stature?

"Darwinism" and "neo-darwinism" are touted by the faithful as the great unifying concepts in modern biology - which is ludicrously untrue. They are concepts as unifying as Christianity, Mohammedan- ism or the general belief in a deity. They serve less to perpetuate Darwin's honoured place in science than to justify the claims of acolytes to orthodoxy. They are not as useful as guides to research workers as is claimed and can be excuses for sloppy thinking and the stifling of promising alternatives.

When a graduate student, I ate many meals at Christ's College, Cambridge, under Darwin's eye. Possibly, I now risk excoriation for suggesting that the memory of perhaps the most distinguished alumnus of the college should be perpetuated differently. In justification I invoke the memory of another pre-eminent member of the same college and suggest that Paradise Lost could be followed by Paradise Regained; Darwin's memory should be neither a crutch nor a club.

Fisheries Research Branch,

T.D. ILES

Scotia-Fundy Region,

Biological Station, St Andrews,

New Brunswick EOG $2 X O$, Canada

Sinclair, M. Nature 320, 580 (1986)

2. Halstead B. Nature 317, 587-589 (1985).

3. Halstead, B. New Sci, 100, 940-941 (1983).

4. Ridley, M. Nature 318, 124-125 (1985).

\section{Dioxin risk}

SIR-We object to your publication of the letter by Drs Alastair Hay and Ellen Silbergeld ("Assessing the risk of dioxin exposure", Nature 315, 102; 1985) because they do not disclose their "hidden affiliation".

Both Hay and Silbergeld have been paid consultants to lawyers representing plaintiffs in a lawsuit against Monsanto Company. Although both Drs Hay and Silbergeld testified in court under oath, they did not see fit to put their analysis as described in Nature into the record.

Allan M. Ford W.J. MCCARVILLE

Monsanto Company,

800 N. Lindbergh Boulevard,

St Louis, Missouri 63167, USA

Hay and Silbergeld reply: It is true that we appeared as expert witnesses in a lawsuit against Monsanto. We criticized Monsanto epidemiology studies while under oath. We regret that Ford and McCarville do not comment on the substance of our critique.

Alastair Hay

Department of Chemical Pathology,

University of Leeds,

Leeds LS2 9NL, UK

Ellen Silbergeld

Environmental Defense Fund,

1525 Eighteenth Street, NW,

Washington, DC 20036, USA

- Contributors who fail to disclose affiliations are in danger of being thought to mislead their readers - Editor, Nature. 